response and ACR 70 criteria were determined after 12 weeks of treatment with a fixed schedule methotrexate and prednisone. Physician perceived remission (PhR) was defined as a global assessment of $\leq 20$ on a visual analogue scale, phrased: "How active do you think the RA of your patient is today?". Patient perceived remission (PatR) was phrased as: "Would you say that, at this moment, your disease activity is as good as gone? Yes/no". In patients in PhR, the change in components of the DAS44 and questions of the Rheumatoid Arthritis Impact of Disease (RAID) and Health Assessment Questionnaire (HAQ) were compared between patients in and not in self-perceived remission.

Results: The agreement on remission between patients and physicians was $64 \%$ and was dependent of the definition of remission. In Boolean remission, EULAR good response and ACR70 remission agreement was: $86 \%, 63 \%$ and $80 \%$ respectively (table). Patients in PhR, the patients in PatR had more improvement on all RAID subdomains. There were no significant differences in clinical outcomes (ESR was significantly different at baseline, but not after 12 weeks; see figure).

Figure. Comparison in improvement in patient reported and clinical outcomes after 12 weeks ol treatment, in patients in physician remission, who are and are not in self-perceived remission.

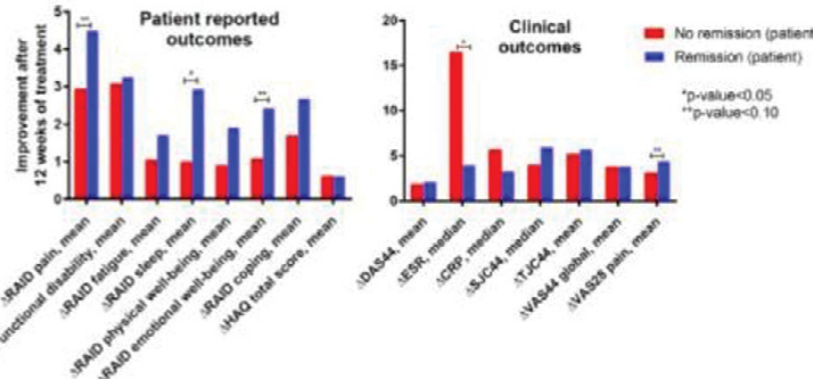

Conclusions: Two-third of the patients agreed with the physician on being in remission. In all different definitions for remission, this discordance between physician and patient on perceived remission remained similar. Patients in selfperceived remission had more improvement in components of the RAID, but not in clinical outcomes. Further research is needed to identify domains of patients perceived remission.

Disclosure of Interest: None declared

DOI: 10.1136/annrheumdis-2017-eular.3406

\section{AB0278 ULTRASOUND EXAMINATION IN DIAGNOSIS OF EARLY RHEUMATOID ARTHRITIS}

W. Hamdi ${ }^{1}$, S. Miladi ${ }^{1}$, K. Matallah ${ }^{1}$, M. Bouaziz ${ }^{2}$, D. Kaffel ${ }^{1}$, I. Zouch ${ }^{1}$, M.M. Kchir ${ }^{1}$. ${ }^{1}$ Rheumatology department; ${ }^{2}$ Radiology department, Institute Kassab of Orthopedics, Manouba. Tunisia, Tunis, Tunisia

Background: Fortunately, management of RA at the early stage has become possible thanks to both the emergence of new biotherapies and the strategy treat to target. Musculoskeletal ultrasound (US) is a potent tool for the detection of synovitis, effusion and bone erosion in RA.

Objectives: The aim of this study was to assess the contribution of US in diagnosing RA at the early stage of the disease.

Methods: A cross-sectional study was performed during 2 years. Patients with a history of inflammatory joint pain for $\geq 6$ weeks and $\leq 2$ years with synovitis of at least one joint were enrolled in this study. All patients underwent clinical assessement, laboratory tests and plain radiography of hands and feet.US was assessed within one week of clinical examination. Synovitis and erosion were defined according to the OMERACT.

Results: One hundred patients were included in this study with an average age of $51,8 \pm 14,6$ years-old. Female outnumbered male with a sex ratio of 3,8 . The mean duration of the disease was $10,9 \pm 7,4$ months. When admitted to our department and after clinical examination it was found that $31 \%$ of patients presented polyarthritis, $4 \%$ had oligoarthritis and $7 \%$ suffered from monoarthritis. US findings: US was found to be more sensitive than clinical examination to detect synovitis. Among the 2200 joints assessed by US, a synovitis was detected in $81 \%$ patients, an intra-articular effusion in $36 \%$ patients and PD signals in $51 \%$ patients. Also, flexor tenosynovitis were present in $55 \%$ patients and extensor tenosynovitis in $59 \%$ patients. Erosions were more detected in plain radiography $(70 \%)$ than in US $(41 \%)$. Clinical parameters (VAS, duration of morning stiffness, number of night awakens, TJC) were not correlated with most US findings. Nevertheless, correlation was detected for US effusion $(r=0,250, p=0,028)$ and for US Doppler $(r=0,289, p=0,011)$ with SJC. PDUS examination correlated with CRP results $(r=0,302, p=0,023)$ but not with ESR results. A significant, positive correlation was observed between erosions in X-rays or US assessment $(r=0,342$, $p=0,002)$. The US detected synovitis in $25 \%$ of patients who had no swollen joint at the clinical examination when admitted to our department and had detected erosions in $9 \%$ of patients having negative plain $X$ rays.

Conclusions: Ultrasound appears as a sensitive tool to detect subclinical synovitis (25\%) and infra- radiological erosions (9\%). It helps us to make an early diagnosis and start appropriate treatment before the onset of irreversible joint destruction.
Disclosure of Interest: None declared

DOI: 10.1136/annrheumdis-2017-eular.6230

\section{AB0279 HIGH RATE OF DISABILITY PENSION IN CHILEAN RHEUMATOID ARTHRITIS PATIENTS WITHOUT ACCESS TO BIOLOGICS. HOSPITAL PADRE HURTADO EXPERIENCE}

S.E. Ibáñez Vodnizza, O. Valenzuela, F. Silva, M.J. Villar. Rheumatology department, Clínica Alemana de Santiago/Hospital Padre Hurtado, Santiago, Chile

Background: Until the year 2016, most of the Chilean rheumatoid arthritis patients in the public health system did not have acces to biologic treatment. Now the access is limited to those with high disease activity (DAS $28>5.1$ ).

Objectives: Our main objective was to evaluate the rate of patients benefited by disability pension within the group of rheumatoid arthritis patients seen in our center, before the introduction of biologic treatment for those with high disease activity. Our secondary objective was to estimate the association between having a disability pension and the characteristics of the patients.

Methods: Consecutive rheumatoid arthritis patients (according to the ACR 2010 criteria), 18 years old or older, that attended to our rheumatology consult between September and December of 2015, were included. Patients with other types of pensions (retirement) were excluded. Information about work status, gender, age, years since diagnosis, medications used, DAS 28 ESR and its variables was collected.

Results: 104 patients were included. $38.5 \%$ had a disability pension. We found significant differences between the patients with and without disability pensions for age, years since diagnosis, tramadol use, the number of tender joints, the number of swollen joints and DAS 28 ESR (Table 1). After multivariate logistic regression, age (OR $1,95 \% \mathrm{Cl} 1.02-1.15)$, tramadol use (OR $0.3,95 \% \mathrm{Cl}$ $0.08-0.92$ ) and the number of swollen joints (OR 1.4, 95\% Cl 1-1.96) continued to be significantly associated.

Table 1. Disease characteristics

\begin{tabular}{lcccc}
\hline & All & $\begin{array}{c}\text { Without Disability } \\
\text { Pension }\end{array}$ & $\begin{array}{c}\text { With Disability } \\
\text { Pension }\end{array}$ & P \\
\hline Number of patients (\%) & $104(100)$ & $64(61.5)$ & $40(38.5)$ & NA \\
Female (\%) & $86(82.7)$ & $53(82.8)$ & $33(82.5)$ & NS \\
Age (median, IQR) & $55.5(15)$ & $52.5(18)$ & $58(15)$ & 0.002 \\
Years since diagnosis (median, IQR) & $8.8(12.2)$ & $5.8(8.2)$ & $12.3(19.1)$ & $<0.001$ \\
Number of DMARDs used (median, IQR) & $2(2)$ & $1(2)$ & $2(2)$ & NS \\
Prednisone users (\%) & $89(85.6)$ & $52(81.3)$ & $37(92.5)$ & NS \\
NSAIDs users (\%) & $75(72.1)$ & $46(71.9)$ & $29(72.9)$ & NS \\
Acetaminophen users (\%) & $68(65.4)$ & $39(60.9)$ & $29(72.5)$ & NS \\
Tramadol users (\%) & $35(33.7)$ & $13(20.3)$ & $22(55)$ & 0.001 \\
Number of tender joints (median, IQR) & $4(6)$ & $3(5)$ & $6(11)$ & 0.018 \\
Number of swollen joints (median, IQR) & $2(4)$ & $1(4)$ & $3(8)$ & 0.012 \\
ESR (median, IQR) & $20.5(21)$ & $16.5(18)$ & $25(31)$ & NS \\
VAS pain (median, IQR) & $60(40)$ & $60(40)$ & $80(40)$ & NS \\
DAS 28 ESR (mean, SD) & $4.5(1.6)$ & $4.1(1.4)$ & $5(1.8)$ & 0.026 \\
\hline IQR
\end{tabular}

$\mathrm{IQR}=$ interquartile range, DMARDs $=$ Disease-Modifying Antirheumatic Drugs, NSAIDs = Nonsteroidal anti-inflammatory drugs, ESR $=$ Erythrocyte Sedimentation Rate, VAS $=$ Visual Analog Scale, DAS = Disease Activity Score, NS = Not significant.

Conclusions: Near forty percent of our rheumatoid arthritis patients, that did not have access to biologic treatment, were being paid a disability pension, and this condition was significatly associated with more years of age, tramadol use, and the number of swollen joints. The mean DAS 28 ESR in the patients with disability pension was 5 . The limit of a DAS $28>5.1$ to authorize the use of biologic treatment possibly will not help to reduce the rate of patients with disability pension in our group.

Disclosure of Interest: None declared

DOI: 10.1136/annrheumdis-2017-eular.2557

\section{AB0280 INFLUENCE OF HLA CLASS II ANTIGEN (DRB1 AND DQB1) ON THE PRODUCTION OF ANTI-CYCLIC CITRULLINATED PEPTIDE ANTIBODIES IN A TUNISIAN POPULATION}

S. Boussaid ${ }^{1}$, S. Kochbati ${ }^{2}$. ${ }^{1}$ Departement of Rheumatologie, la Rabta Hospital; ${ }^{2}$ Departement of Rheumatologie, Habib Thameur Hspital, tunis, Tunisia

Background: Rheumatoid arthritis (RA) is the most common chronic inflammatory rheumatism. It's a complex autoimmune disorder. The aim of this study is to focus on the relationship between HLA-DRB1 genes and RA specific antibodies against cyclic citrullinated peptides (anti-CCP antibodies).

Methods: This prospective study was performed on a total of 81 Tunisian patients with rheumatoid arthritis. All patients fulfilled the American College of Rheumatology (ACR 1987) criteria for RA. For each patient we assessed DNA and serum samples. The DNA was extracted from lymphocytes using a commercial kit (Quiagen). The HLA class II (DQB1 and DRB1) was performed by Polymerase Chain Reaction technique Specifying-sequence primers (PCR-SSP). The specific products of PCR were analyzed by $2.5 \%$ agarose gel electrophoresis. All tests include positive and negative controls appropriate for each blood sample. The phenotypes of patients were obtained through the Software One Lambda DNA/SOFTWARE (SSP2L-generic DRB/DQB). 